\title{
Favourite movie stars, their tobacco use in contemporary movies, and its association with adolescent smoking
}

Jennifer J Tickle, James D Sargent, Madeline A Dalton, Michael L Beach, Todd F Heatherton

Department of Psychological and Brain Sciences, Dartmouth College, Hanover, New Hampshire, USA J J Tickle

T F Heatherton

Departments of Pediatrics and Community \& Family Medicine, and the Norris Cotton Cancer Center, Dartmouth

Medical School,

Hanover

J D Sargent

Department of

Pediatrics, and the

Norris Cotton Cancer

Center, Dartmouth

Medical School,

Hanover

M A Dalton

Department of Community \& Family Medicine, Dartmouth Medical School, and

Veterans' Affairs

Medical Center, White

River Junction,

Vermont, USA

M L Beach

Correspondence to: Jennifer J Tickle, 6207

Moore Hall, Department of Psychological and Brain Sciences, Dartmouth College Hanover, NH 03755, USA Jennifer.Tickle

Dartmouth.edu

Received 27 January 2000 and in revised form

2 June 2000

Accepted 23 June 2000

\begin{abstract}
Objective-To assess the relation between adolescents' favourite movie stars, the portrayal of tobacco use by those stars in contemporary motion pictures, and adolescent smoking.

Design and setting-632 students (sixth to 12th grade, ages 10-19 years) from five rural New England public schools completed a voluntary, self administered survey in October 1996. The survey assessed tobacco use, other variables associated with adolescent smoking, and favourite movie star. In addition, tobacco use by 43 selected movie stars was measured in films between 1994 and 1996. Outcome measures-Students were categorised into an ordinal five point index (tobacco status) based on their smoking behaviour and their smoking susceptibility: non-susceptible never smokers, susceptible never smokers, non-current experimenters, current experimenters, and smokers. We determined the adjusted cumulative odds of having advanced smoking status based on the amount of on-screen tobacco use by their favourite film star.
\end{abstract}

Results-Of the 43 stars, $65 \%$ used tobacco at least once, and $42 \%$ portrayed smoking as an essential character trait in one or more films. Stars who smoked more than twice in a film were considered smokers. For adolescents whose favourite stars smoked in only one film, the odds of being higher on the smoking index was 0.78 (95\% confidence interval (CI) 0.53 to 1.15). For adolescents whose favourite stars smoked in two films, the odds of being higher on the smoking index was 1.5 (95\% CI 1.01 to 2.32). For adolescents whose favourite stars smoked in three or more films (Leonardo DiCaprio, Sharon Stone, John Travolta), the odds of being higher on the smoking index was $3.1(95 \%$ CI 1.34 to 7.12). Among never smokers ( $n=281)$, those who chose stars who were smokers in three or more films were much more likely to have favourable attitudes toward smoking (adjusted odds ratio 16.2, $95 \%$ CI 2.3 to 112 ).

Conclusions-Adolescents who choose movie stars who use tobacco on-screen are significantly more likely to have an advanced smoking status and more favourable attitudes toward smoking than adolescents who choose non-smoking stars. This finding supports the proposition that the portrayal of tobacco use in contemporary motion pictures, particularly by stars who are admired by adolescents, contributes to adolescent smoking. (Tobacco Control 2001;10:16-22)

Keywords: adolescent smoking; movies; media influences

Understanding factors that contribute to the adoption of smoking by youth is an essential element of tobacco control. A variety of theories have been proposed to explain tobacco use among adolescents. One of the most popular is social learning theory, ${ }^{1}$ which emphasises the importance of the interplay between individual traits and the environment. Important social learning factors in children include parents and peers, but also socialisation by mass media. The view that exposure to smoking in mass media can have an impact on tobacco related attitudes and behaviours is articulated in the Institute of Medicine document, "Growing up tobacco free"2: "In developing norms, adolescents look to the greater social environment for concepts of adult identity, particularly the behaviour of leaders, heroes, and film stars, and in the media."

Despite the popularity of the idea that smoking in movies could be a significant social learning factor in adolescents, there has been little empirical study of this notion. Adolescents' exposure to motion pictures has increased in the past two decades. Most Americans now have access to movies on videotape, and adolescents today view an average of two movies per week. ${ }^{3}$ In addition, smoking in movies is prevalent; a recent study of films released between 1990 and 1996 found that $57 \%$ of major movie characters used tobacco. ${ }^{4}$ Smoking is common even in G (general viewing audience) rated films. ${ }^{5}$ Given access to video rentals, cable television, and traditional movie theatres, it is likely that adolescents are exposed to a great deal of smoking in movies.

Recently, Distefan and colleagues ${ }^{6}$ reported a relation between preference for particular stars and susceptibility to smoking in a sample of California adolescents. They found that adolescent tobacco users differed from never smokers in their choice of favourite stars, and that many of the stars selected by tobacco users were smokers in real life or portrayed 
characters who used tobacco in films. In addition, adolescent never smokers who chose a favourite star of adolescent smokers were almost 1.5 times more likely to be susceptible to smoking. The risk variable in the Distefan study - choice of a favourite star of smokerswas whether the star was chosen by adolescent smokers, not whether the star actually used tobacco in movies.

In this study we assess directly the on-screen smoking behaviour of movie stars favoured by a sample of adolescents, independent of the adolescent's smoking status, and then evaluate the association between whether the actor smokes in movies and adolescent smoking. Our hypothesis is that adolescents who choose favourite stars who display higher levels of smoking in film will be further along in their acquisition of smoking behaviour than adolescents who select stars who smoke less.

\section{Methods}

Five rural schools in Vermont and New Hampshire participated in a survey that was conducted for a separate purpose but contained items relevant to the current hypothesis. A detailed description of the sample and survey methods has been published. ${ }^{7}$ Briefly, school selection was based on the following criteria: (1) schools enrolled students in grades 6 through 12 (ages 10-19 years); (2) schools were located in rural communities in Vermont or New Hampshire, within a two hour driving distance from Lebanon, New Hampshire; (3) schools served communities that were in the lowest quartiles for median household income and percent of adults who completed high school for each state. Of 13 schools initially contacted and asked to participate, five were surveyed in October 1996: three in New Hampshire (school A, grades 9-12, 469 students; school B, grades 6-7, 169 students; school C, grades $8-12,378$ students) and two in Vermont (school D, grades 7-12, 288 students; school E, grades 7-12, 543 students). The populations served by participating schools were not different from non-participating schools.

Participating students were asked to complete voluntarily an anonymous, self administered questionnaire in a classroom or assembly setting. Passive parental consent was obtained for the administration of this survey in school by mailing consent forms to students' homes 1-2 weeks before the survey date. Parents were asked to contact the school if they did not want their child to participate in the survey. The Dartmouth College committee for the protection of human subjects approved the study and consent procedures.

STUDENT SAMPLE AND STAR PREFERENCE Surveys were collected from 1543 students, representing between $79-95 \%$ of the students in each school. Eighteen per cent of these questionnaires were discarded because students indicated they had not been honest, because there were five or more logically inconsistent responses, or because of incomplete data on the variables examined in this report. Completed surveys were obtained from 1265 students. Each student's favourite star was surveyed in the sample by asking the following open ended question: "Who is your favourite movie/film star?" Of 1236 respondents to this question, $79 \%$ were able to identify a favourite actor/actress, $7.9 \%$ mentioned a movie title or cartoon (coded non-response), and $13.2 \%$ did not name a favourite actor/actress. Because the question was open ended, 228 stars were named in response to the question. Evaluation of smoking status for all movies for each of these stars would have required us to view some 2000 movies. In order to reduce the number of movies in the sample, we restricted our analysis of star smoking behaviour to actors and actresses who were selected by at least five students in the sample and who had appeared in films within the three years before the study (1994 to 1996). We excluded one further actress, Pamela Anderson, who was likely selected by students who knew of her from television rather than film. These criteria resulted in a sample of 632 students who had selected one of 43 film stars. Retained students did not differ from those who were excluded with respect to smoking status, grade in school, or exposure to tobacco advertising. They were significantly less likely to have family members who smoked and were significantly more likely to be male and have below average grades.

\section{VALIDITY AND RELIABILITY}

Details of the procedures used to increase the validity and reliability of the self reports have been published. ${ }^{7}$ We assured anonymity ${ }^{8}$ and employed a bogus pipeline procedure (using a saliva sample) ${ }^{9}$ to increase the validity of reports of smoking. In addition, self reports of tobacco use by eighth, 10th, and 12th graders were similar to those of the nationally representative sample of students surveyed in the 1996 "Monitoring of the future survey" (MTFS). ${ }^{710}$ The test-retest reliability of all covariates was evaluated in a separate survey of 114 students who completed the questionnaire twice, with a five week interval between the two surveys. The $\kappa$ statistic ${ }^{11}$ was used to measure agreement between test and retest answers for categorical and ordinal data. It was not necessary to exclude any variable because of an unacceptably low $\kappa(<0.7) .{ }^{12}$

SMOKING EXPERIENCE AND SUSCEPTIBILITY TO SMOKING

We categorised students' smoking status based on two variables that describe attitudes and behaviour and have been shown to predict later smoking in prospective cohort studies of adolescents. Collins and colleagues ${ }^{13}$ indicate that the best predictor of future smoking is cigarette use at baseline. Lifetime smoking experience was determined by students' answers to two questions: "Have you ever tried smoking cigarettes, even a few puffs?" and "How many cigarettes have you smoked in your whole life?" "Never smokers" were defined as those who answered "no" and 
"none," respectively. "Experimental smokers" were those who had smoked fewer than 100 cigarettes, and "smokers" were those who had smoked 100 or more. Lifetime use of more than 100 cigarettes has been used to classify ever smokers in studies of adults and is used in the USA to define an individual who has been dependent on cigarettes in the past. ${ }^{14}$ Experimental smokers were further characterised by whether or not they had smoked in the past 30 days.

Pierce and colleagues have shown that a variable that describes attitudes toward smoking (termed "susceptibility to smoking") can be combined with measures of experience to predict more accurately later smoking behaviour. ${ }^{15} 16$ Susceptibility to smoking is determined from responses when asked, "How likely are the following?: (1) I will smoke a cigarette in the next six months; (2) I would smoke a cigarette if a friend offered me one." Any individual who cannot definitely rule out smoking in the future by answering "definitely not" for both of these statements is deemed susceptible. Prospective studies show that susceptible never smokers are more likely to begin using cigarettes in the future. We combined the lifetime smoking experience, current smoking, and susceptibility measures into a five point, ordinal smoking status index: non-susceptible never smokers, susceptible never smokers, non-current experimenters, current experimenters, and smokers. Test-retest reliability $\kappa$ for this index was 0.95 .

FILM TOBACCO USE VARIABLES

We reasoned that adolescents are more likely to be exposed to contemporary movies that their favourite stars have appeared in, and they are more likely to attend to behaviours portrayed by those stars. Thus, we evaluated smoking in all films for the three years preceding the survey (1994 to 1996) in which the favourite stars appeared as major or minor characters. Documentaries, made-for-TV movies, and films in which the star was the voice of a character (as in animated films) were excluded. This resulted in a list of 178 movies and 209 roles (some movies had more than one actor).

Each film was then viewed to determine whether the actors or actresses of interest smoked in the film. Tobacco use was measured by a variable in the following manner: $0=$ did not smoke or smoked only infrequently ( $\leqslant$ two times); $1=$ smoked frequently ( $>$ two times). We used this criteria as a conservative measure of smoking, since only characters who were shown using tobacco multiple times during the film (as opposed to a lone celebratory cigar, for instance) were categorised as smokers. The star tobacco use index is the number of movies during the 1994 to 1996 sample frame in which a star was scored a " 1 " on the tobacco use item. Box office success for each star was measured by the number of films the star was in that were in the top 50 for box office gross in the year of the film's release.
CONTROL VARIABLES

Various characteristics of adolescents and their social environments are known to affect their decisions to smoke. In evaluating the relation between favourite movie star and smoking behaviour, we controlled for the effects of other individual and environmental attributes known to be associated with smoking by including these variables as covariates in multivariate analyses. These variables included family and friend smoking, receptivity to tobacco promotions, grade in school, sex, and perceived school performance. Family and friends smoking was measured using the four categories of Evans and colleagues: no friends or family, family only, friends only, family and friends. ${ }^{17}$ Students were categorised as receptive to tobacco promotions if they owned or were willing to use a tobacco promotional item. Ethnicity and school area socioeconomic status (SES) are also known predictors of smoking susceptibility, but the ethnicity and SES of this sample were homogeneous (the students were more than $90 \%$ white and the sample communities were in the lowest quartile for SES for the respective states), so these variables were not included as covariates in the model.

STATISTICAL ANALYSIS

We evaluated the association between star tobacco use and adolescent tobacco status using proportional odds models with the smoking index as the dependent variable. Proportional odds models estimate the likelihood of being classified higher in smoking status given the preference for stars who portrayed tobacco use, adjusting for potential confounders. Proportional odds models provide cumulative odds ratios (ORs) that model the probability of being in any higher category on the smoking index. This method allows for a multi-level dependent variable and preserves information that would be lost using a dichotomous variable. To assess the robustness of the effect between preferred star smoking behaviour and adolescent smoking level, a sensitivity analysis was conducted by deleting variables from the model or by deleting individual stars from the analysis. The association between star tobacco use and susceptibility to smoking among never smokers was evaluated using multiple logistic regression.

\section{Results}

DESCRIPTION OF THE SAMPLE

The age of the sample ranged from 10-19 years and included sixth through 12th graders (table 1). Social exposure to smoking was moderately high for this group. Only $12 \%$ of the sample reported no family members or friends using tobacco, and over half of the sample reported having both family members and friends who smoke. The sample was fairly evenly distributed across all levels of the smoking index, with smaller proportions of students in transitional phases of the index (susceptible never smoker and current experimenter stages). 
Table 1 Characteristics of the adolescent sample

\begin{tabular}{|c|c|}
\hline Characteristic & Number (\%) \\
\hline \multicolumn{2}{|l|}{ Grade } \\
\hline 6 & $30(4.8)$ \\
\hline 7 & $72(11.4)$ \\
\hline 8 & $70(11.1)$ \\
\hline 9 & $122(19.3)$ \\
\hline 10 & $128(20.3)$ \\
\hline 11 & $106(16.8)$ \\
\hline 12 & $104(16.5)$ \\
\hline \multicolumn{2}{|l|}{ Sex } \\
\hline Female & $367(58.1)$ \\
\hline Male & $265(41.9)$ \\
\hline \multicolumn{2}{|l|}{ Family and friend smoking } \\
\hline None & $77(12.2)$ \\
\hline Family only & $40(6.3)$ \\
\hline Friends only & $185(29.3)$ \\
\hline Both & $330(52.2)$ \\
\hline \multicolumn{2}{|l|}{ Smoking status ${ }^{\star}$} \\
\hline Non-susceptible/never smoker & $236(37.3)$ \\
\hline Susceptible/never smoker & $47(7.4)$ \\
\hline Non-current/experimenter & $165(26.1)$ \\
\hline Current/experimenter & $55(8.7)$ \\
\hline Smoker & $129(20.4)$ \\
\hline \multicolumn{2}{|c|}{$\begin{array}{l}\text { ״A respondent is susceptible to smoking if unable to answer } \\
\text { "definitely not" to the following questions: "Do you think you } \\
\text { will try a cigarette in the next } 6 \text { months?" and "Would you } \\
\text { smoke a cigarette if your friend offered you one?". } \\
\text { Experimental smokers have smoked } 1-99 \text { cigarettes in their } \\
\text { lifetime, and smokers have smoked } \geqslant 100 \text { cigarettes in their } \\
\text { lifetime. Current smoking is smoking within the past } 30 \text { days. }\end{array}$} \\
\hline
\end{tabular}

Table 2 Stars chosen by adolescents and their tobacco use scores for films from 1994 to 1996

\begin{tabular}{|c|c|c|c|c|}
\hline Actor name & $\begin{array}{l}N \text { (students who } \\
\text { chose this actor) }\end{array}$ & $\begin{array}{l}\text { Per cent (of } \\
\text { all) }\end{array}$ & $\begin{array}{l}N \text { (all } \\
\text { movies) }\end{array}$ & $\begin{array}{l}N \text { (top } 50 \\
\text { movies) }\end{array}$ \\
\hline \multicolumn{5}{|l|}{ Star tobacco use $=0$} \\
\hline Sandra Bullock & 17 & 2.7 & 6 & 4 \\
\hline John Candy & 5 & 0.8 & 2 & 0 \\
\hline Sean Connery & 6 & 1.0 & 4 & 3 \\
\hline Tom Cruise & 24 & 3.8 & 3 & 3 \\
\hline Claire Danes & 7 & 1.1 & 6 & 2 \\
\hline Chris Farley & 6 & 1.0 & 4 & 0 \\
\hline Harrison Ford & 7 & 1.1 & 3 & 2 \\
\hline Mel Gibson & 21 & 3.3 & 4 & 4 \\
\hline Tom Hanks & 15 & 2.4 & 3 & 2 \\
\hline Andrew Keegan & 6 & 1.0 & 3 & 1 \\
\hline Eddie Murphy & 10 & 1.6 & 3 & 2 \\
\hline Chris O'Donnell & 19 & 3.0 & 6 & 2 \\
\hline Rosie O'Donnell & 6 & 1.0 & 8 & 1 \\
\hline Michelle Pfeiffer & 5 & 0.8 & 5 & 4 \\
\hline Julia Roberts & 7 & 1.1 & 6 & 1 \\
\hline Adam Sandler & 23 & 3.6 & 5 & 1 \\
\hline Devon Sawa & 17 & 2.7 & 4 & 1 \\
\hline Arnold Schwarzenegger & 18 & 2.9 & 4 & 4 \\
\hline Steven Seagal & 23 & 3.6 & 4 & 3 \\
\hline Alicia Silverstone & 17 & 2.7 & 4 & 1 \\
\hline Wesley Snipes & 11 & 1.7 & 5 & 4 \\
\hline Sylvester Stallone & 14 & 2.2 & 4 & 2 \\
\hline Patrick Swayze & 6 & 1.0 & 3 & 1 \\
\hline Jonathan Taylor-Thomas & 7 & 1.1 & 2 & 1 \\
\hline Jean-Claude Van Damme & 36 & 5.7 & 5 & 2 \\
\hline \multicolumn{5}{|l|}{ Star tobacco use $=1$} \\
\hline Jim Carrey & 65 & 10.3 & 6 & 6 \\
\hline Johnny Depp & 6 & 1.0 & 4 & 0 \\
\hline Morgan Freeman & 6 & 1.0 & 5 & 2 \\
\hline Val Kilmer & 8 & 1.3 & 3 & 2 \\
\hline Demi Moore & 13 & 2.1 & 5 & 1 \\
\hline Meg Ryan & 8 & 1.3 & 5 & 3 \\
\hline Will Smith & 13 & 2.1 & 2 & 2 \\
\hline Robin Williams & 21 & 3.3 & 7 & 5 \\
\hline Bruce Willis & 8 & 1.3 & 7 & 4 \\
\hline \multicolumn{5}{|l|}{ Star tobacco use $=2$} \\
\hline Drew Barrymore & 14 & 2.2 & 6 & 2 \\
\hline Robert De Niro & 7 & 1.1 & 6 & 3 \\
\hline Whoopi Goldberg & 5 & 0.8 & 12 & 2 \\
\hline Brad Pitt & 91 & 14.4 & 6 & 5 \\
\hline Keanu Reeves & 7 & 1.1 & 7 & 2 \\
\hline Christian Slater & 8 & 1.3 & 5 & 2 \\
\hline \multicolumn{5}{|l|}{ Star tobacco use $=3$ or more } \\
\hline Leonardo DiCaprio & 5 & 0.8 & 5 & 1 \\
\hline Sharon Stone & 5 & 0.8 & 6 & 2 \\
\hline John Travolta & 9 & 1.4 & 6 & 5 \\
\hline
\end{tabular}

DESCRIPTION OF STAR PREFERENCES AND TOBACCO USE BY THOSE STARS

Forty three stars (11 actresses and 32 actors) were selected by at least five adolescents. Table 2 presents a list of these stars (sorted by the star tobacco use index), the number and percentage of adolescents who selected that star, and information about the total number of movies and top 50 movies for that star between 1994 and 1996. The percentage of adolescents who selected each star ranged from $0.8-14 \%$ of the sample, with the most popular actor being Brad Pitt, chosen by 91 adolescent girls. The number of movies released between 1994 and 1996 for each star ranged from 2-12 (mean 4.9) and the number of top 50 movies for each star ranged from 0-6 (mean 2.3). All but three of the stars had appeared in a top 50 movie during this time period, an indication of the popularity of these stars. Fifteen $(35 \%)$ of the 43 stars did not smoke in any films during the period, but the remaining $28(65 \%)$ did smoke at least one time on-screen during the three year time period. Eighteen stars (41\%) were classified as smokers using our star smoking index, and three of these stars (Leonardo DiCaprio, Sharon Stone, John Travolta) were coded as smokers in four movies.

We used the Wald test to determine whether including the highest category of the star smoking variable added any meaning to our results. We reasoned that addition of the variable was worthwhile if it substantiated a dose effect - that is, the coefficient was significantly higher than the coefficients for adolescents who chose a star who had major smoking in one or two movies. Even though there were few students in the highest category, the coefficient was significantly different from the coefficient for students who chose a star who smoked in one movie for both regression analyses reported in the results. Next, we examined the residuals for those 19 individuals who chose a star in the highest smoking category to see if the results were anomalous or driven by one or two individuals. The distribution of the residuals for these adolescents were not different from the distribution for the rest of the sample. After performing these analyses, we chose to retain this highest category of star smoking as a covariate in the models.

RELATIONS BETWEEN THE VARIABLES

Table 3 reports the associations between star tobacco use, adolescent smoking status, and each of the covariates. Approximately half $(53 \%)$ of the adolescents selected stars who were not smokers on-screen. There were significant relations between star, the sex of the respondent, and the smoking status of the respondent (all probability values $\mathrm{p}<0.005$ ). There was a marginal association between star tobacco use and grade in school $(\mathrm{p}=0.08)$, with older adolescents tending to prefer stars who smoke more.

ASSOCIATION OF FAVOURITE STAR TOBACCO USE AND ADOLESCENT SMOKING

We determined the adjusted cumulative odds of having a higher smoking status given a 
Table 3 Association of star tobacco use and other variables

\begin{tabular}{|c|c|c|c|c|c|}
\hline \multirow[b]{2}{*}{ Variable } & \multicolumn{4}{|c|}{$\begin{array}{l}\text { Favourite star tobacco use score (\% } \\
\text { in each category) }\end{array}$} & \multirow[b]{2}{*}{ p Value } \\
\hline & 0 & 1 & 2 & $\geqslant 3$ & \\
\hline Total sample & 52.7 & 23.4 & 20.9 & 3.0 & \\
\hline \multicolumn{6}{|l|}{ Respondent characteristics } \\
\hline \multicolumn{6}{|l|}{ Grade in school } \\
\hline 6 & 76.7 & 20.0 & 3.3 & 0.0 & \multirow[t]{7}{*}{0.08} \\
\hline 7 & 58.3 & 31.9 & 8.3 & 1.4 & \\
\hline 8 & 55.7 & 18.6 & 21.4 & 4.3 & \\
\hline 9 & 51.6 & 26.2 & 18.9 & 3.3 & \\
\hline 10 & 50.8 & 21.9 & 24.2 & 3.1 & \\
\hline 11 & 50.9 & 22.6 & 22.6 & 3.8 & \\
\hline 12 & 45.2 & 21.2 & 30.8 & 2.9 & \\
\hline \multicolumn{6}{|l|}{ Sex } \\
\hline Female & 44.4 & 19.9 & 33.0 & 10.0 & \multirow{2}{*}{$<0.0001$} \\
\hline Male & 64.1 & 28.3 & 4.2 & 2.7 & \\
\hline \multicolumn{6}{|l|}{ Family and friend smoking } \\
\hline None & 49.4 & 32.5 & 15.6 & 2.6 & \multirow[t]{4}{*}{0.4} \\
\hline Family only & 62.5 & 17.5 & 15.0 & 5.0 & \\
\hline Friends only & 52.4 & 22.7 & 20.5 & 4.3 & \\
\hline Both & 52.4 & 22.4 & 22.4 & 2.1 & \\
\hline \multicolumn{6}{|l|}{ Receptivity to tobacco promotions } \\
\hline No & 51.1 & 25.0 & 20.2 & 3.6 & \multirow[t]{2}{*}{0.2} \\
\hline Yes & 56.2 & 19.8 & 22.4 & 1.6 & \\
\hline \multicolumn{6}{|l|}{ Smoking status ${ }^{\star}$} \\
\hline Non-susceptible/never smoker & 57.2 & 28.4 & 12.7 & 1.7 & \multirow[t]{5}{*}{0.004} \\
\hline Susceptible/never smoker & 42.6 & 27.7 & 23.4 & 6.4 & \\
\hline Non-current/experimenter & 51.5 & 21.8 & 24.2 & 2.4 & \\
\hline Current/experimenter & 54.6 & 16.4 & 21.8 & 7.3 & \\
\hline Smoker & 48.8 & 17.8 & 30.2 & 3.1 & \\
\hline
\end{tabular}

Table 4 Covariate adjusted association between favourite star tobacco use and tobacco status of the respondent $(n=632)$

\begin{tabular}{|c|c|c|c|}
\hline \multirow[b]{2}{*}{ Covariate } & \multicolumn{3}{|c|}{$\begin{array}{l}\text { Proportional odds ratios * (odds of being higher in tobacco } \\
\text { status) }\end{array}$} \\
\hline & $O R$ & $95 \% C I$ & p Value \\
\hline \multicolumn{4}{|c|}{ Tobacco use: favourite star } \\
\hline 0 & Reference & & \\
\hline 1 & 0.78 & 0.53 to 1.15 & 0.2 \\
\hline 2 & 1.53 & 1.01 to 2.32 & 0.046 \\
\hline$\geqslant 3$ & 3.09 & 1.34 to 7.12 & 0.008 \\
\hline \multicolumn{4}{|l|}{ Grade } \\
\hline 6 & Reference & & \\
\hline 7 & 0.81 & 0.34 to 1.95 & 0.6 \\
\hline 8 & 0.83 & 0.35 to 2.00 & 0.7 \\
\hline 9 & 1.86 & 0.82 to 4.20 & 0.1 \\
\hline 10 & 1.41 & 0.63 to 3.17 & 0.4 \\
\hline 11 & 1.48 & 0.65 to 3.36 & 0.3 \\
\hline 12 & 2.65 & 1.15 to 6.10 & 0.02 \\
\hline \multicolumn{4}{|l|}{ Sex } \\
\hline Female & Reference & & \\
\hline Male & 0.85 & 0.60 to 1.19 & 0.3 \\
\hline \multicolumn{4}{|c|}{ Family and friends smoking } \\
\hline None & Reference & & \\
\hline Family only & 1.39 & 0.57 to 3.40 & 0.5 \\
\hline Friends only & 3.23 & 1.71 to 6.09 & $<0.0001$ \\
\hline Family and friends & 9.54 & 5.09 to 17.89 & $<0.0001$ \\
\hline
\end{tabular}

*The odds ratios are adjusted for all other variables listed in the table as well as perceived school performance and ownership of cigarette promotional items.

preference for stars who smoked in their films, after controlling for other factors associated with adolescent smoking (table 4). For adolescents whose favourite stars smoked in only one film, the odds of being higher on the smoking index was 0.78 (95\% confidence interval (CI), 0.53 to 1.15$)$. For adolescents who chose stars who were smokers in two films, the adjusted odds of being higher on the smoking index was 1.5 (95\% CI 1.01 to 2.32 ). For those who chose stars that were smokers in three or more films, the adjusted odds of being higher on the smoking index was 3.1 (95\% CI 1.34 to 7.12 ).

We also examined the relation between star tobacco use and susceptibility among the never smokers in the sample $(\mathrm{n}=281)$ (table 5). Among never smokers, those who chose stars who were smokers in films were much more likely to be susceptible to smoking (adjusted OR $4.8,95 \%$ CI 1.60 to 14.23 , for stars who smoked in two films, and OR 16.2, 95\% CI 2.33 to 112.61 , for stars who smoked in three or more films).

Consistent with previous research, higher grade in school and exposure to friends or both family and friends who smoke were associated with higher levels of adolescent smoking. Because of the association between actor's tobacco use and actor's box office success, we also included box office success in the model; inclusion of this variable did not alter the findings. We tested for an interaction between sex of respondent and tobacco use of favourite star; the interaction term was not significant in either model. We collapsed the grade variable into a dichotomous variable $(0=6-8$ th grade; $1=9-12$ th grade) and tested for an interaction between grade and star tobacco use; the interaction term was not significant. Finally, the results did not change when we re-ran the models excluding (one-at-a-time) individual stars with tobacco use status of 2 or $\geqslant 3$. Thus the results are not determined primarily by one of the tobacco using film stars within these categories.

\section{Discussion}

This research shows a clear relation between on-screen tobacco use by movie stars and higher levels of smoking uptake in the adolescents who admire them. This association appears to be independent of other factors known to predict adolescent smoking, such as smoking by family and peers. It is unlikely that this effect is due to smokers simply paying more attention to on-screen smoking. Instead, the association between star smoking and attitudes that predict smoking (susceptibility) was even stronger among never smokers, suggesting that the influence of movie star smoking begins before experimentation with cigarettes. We believe that this evidence strongly suggests that media portrayals of tobacco use by popular movie stars contribute to adolescent smoking.

It is important to consider the potential public health impact of the portrayal of smoking by these actors and actresses on adolescent smoking. Nearly all adolescents were able to respond with the name of a favourite star, which speaks to the salience of movie stars in this age group. Although the analyses reported here did not distinguish between individual stars within the tobacco use categories, and although we can only speculate about the process of star selection, there were clear preferences for some stars. Brad Pitt, for instance, was selected by $14 \%$ of the adolescents in this sample. Because 
Table 5 Covariate adjusted ${ }^{\star}$ association between favourite star tobacco use and attitudes toward smoking among never smokers $(n=281)$

\begin{tabular}{lllll}
\hline & & \multicolumn{2}{c}{$\begin{array}{c}\text { Adjusted odds ratios (odds of being susceptible } \\
\text { to smokingt) }\end{array}$} \\
\cline { 3 - 5 } Covariate & $N$ (\% susceptible) & OR & $95 \% C I$ & p Value \\
\hline Tobacco use: favourite star & & & & \\
0 & $155(12.9)$ & Reference & & \\
1 & $80(16.3)$ & 2.16 & 0.86 to 5.45 & 0.2 \\
2 & $41(26.8)$ & 4.78 & 1.60 to 14.23 & 0.005 \\
$\geqslant 3$ & $7(42.9)$ & 16.18 & 2.33 to 112.61 & 0.005 \\
Family and friend smoking & & & & \\
None & $67(10.5)$ & Reference & & \\
Family only & $30(10.0)$ & 0.78 & 0.17 to 3.54 & 0.7 \\
Friends only & $98(21.4)$ & 2.88 & 1.03 to 8.00 & 0.042 \\
Family and friends & $88(18.2)$ & 2.28 & 0.78 to 6.66 & 0.1 \\
\hline
\end{tabular}

${ }^{\star}$ Model includes controls for grade, sex, perceived school performance, and ownership of cigarette promotional items. +Students were susceptible to smoking if they could not definitely rule out smoking in the next 6 months or smoking if a peer offered a cigarette.

of his popularity among teens at the time, large numbers could have been affected by his portrayals of smoking. In addition, the popularity of Leonardo DiCaprio, who smoked even more than Brad Pitt, has risen dramatically since this survey, making it possible that his smoking portrayals have influenced an even larger number of adolescents. A full understanding of the impact of star tobacco use on adolescent smoking must include both the relative and absolute effects on the adolescent population. The absolute effects can only be measured with population based surveillance of adolescent star preferences, a limitation to the current study.

There are several other limitations that deserve mention. This study is cross sectional, which does not allow us to establish a causal relation between exposure to stars who smoke and increased smoking among adolescents. It is possible that admiration for stars who smoke does not lead to adolescent smoking. Rather, adolescents who are susceptible to smoking may pay more attention to smokers in films or come to admire those stars who smoke more than adolescents who are less susceptible. Prospective studies are needed to address this question.

Another limitation is that our study allowed students to choose only one star, therefore our measure of smoking exposure is somewhat crude. Also, our measure of star smoking (a conservative two category scale) does not allow us to examine any differences in the portrayal of smoking within films. Given these limitations, we were surprised at the strength of the association. Also, our restriction of movie stars to those nominated by five or more adolescents means that we excluded some actors who might be quite influential on smoking attitudes, albeit for a smaller number of adolescents. Our study examined the effects of portrayals of smoking by the popular movie stars, but may not be representative of all actor portrayals of smoking. Finally, our sample size was relatively small and drawn from a limited number of schools in rural New England serving predominantly poor youth.

The study was not designed to examine potential mediators of the star smokingadolescent smoking relation. One mediator may be the perception of smoking norms.
Movies portray tobacco use among major characters much more often than smoking occurs in real life. ${ }^{4}$ In addition, demographic characteristics of smokers in films do not reflect the demographics of actual smokers, and the negative consequences of tobacco use are rarely portrayed in the movies. ${ }^{4}{ }^{18-21}$ Behaviours perceived as normative are especially likely to be performed, even if the norms are misperceived or inaccurate. ${ }^{22}{ }^{23}$ Therefore, false consensus beliefs about smoking, conveyed in part by media, may promote experimentation among adolescents. ${ }^{24}$

Beyond shaping teens' notions about smoking as normative behaviour, tobacco use by stars could shape positive expectations. Positive expectations are perceptions of the positive gains that might accrue by adopting a behaviour. Positive expectations ("I think I might enjoy smoking") are more strongly correlated with youth smoking than negative expectations ("I think smoking might stain my teeth"). ${ }^{25}$ Adolescents who want to be like stars who smoke may associate more positive expectations with the behaviour, increasing their smoking susceptibility.

Other possible mediators involve self identity. Adolescents who believe smoking fits into their self view are more likely to start smoking because people choose behaviours that are consistent with their self concept. ${ }^{26}$ Self concept ratings of adolescent smokers, as well as susceptible non-smokers, are more similar to their ratings of the prototypical smoker than are the self concept ratings of non-smokers. ${ }^{27-30}$ Adolescents may also initiate behaviours to create a new self image. Media shape views of what is "cool", attractive, and grown up-all things that adolescents are trying to be. Adolescents may perceive relations between these desired aspects of self and behaviours that might help them acquire these self aspects (such as smoking). To the extent that smoking portrayals are consistent with adolescents' actual or ideal self images or a prototype of the ideal group member (that is, being cool), adolescents will be motivated to smoke to align self perceptions with personal ideals. ${ }^{27} 283132$

Although the data obtained in this survey did not allow us to explore these potential mediators of the relation between movie star smoking and adolescent attitudes, we are currently conducting research aimed at delineating these factors and their contributions. The current findings do, however, highlight the potentially enormous impact of media portrayals of smoking on adolescent attitudes towards tobacco use. These results contribute to a growing body of evidence identifying media exposure to smoking as a major contributing factor in adolescent smoking uptake.

In summary, these data suggest that mass media portrayals of smoking among favoured movie stars contribute to adolescent smoking which is, in turn, a causal link in what remains the leading cause of premature death and the number one preventable public health problem in the developed world. 
We are grateful for the editorial assistance of Susan Martin and the helpful comments of Michael Weitzman, MD. This work was supported by National Cancer Institute grants CA-67538 and CA-23108.

1 Bandura A. Self-efficacy: the exercise of control. New York: WH Freeman; 1997

2 Lynch B, Bonnie R. Growing up tobacco free-preventing nicotine addiction in children and youths: a report of the Institute of Medicine. Washington DC: National Academy Press, 1994

3 Rideout VJ, Foehr UG, Brodie M. Kids media at the new millennium: a comprehensive analysis of children's media use. Kaiser Family Foundation Report, November 1999.

4 Stockwell TF, Glantz SA. Tobacco use is increasing in popular films. Tobacco Control 1997;6:282-4.

5 Goldstein AO, Sobel RA, Newman GR. Tobacco and alcohol use in G-rated children's animated films. $\mathscr{f} A M A 1999$ 281:1131-6.

6 Distefan JM, Gilpin EA, Sargent JD, et al. Do movie stars encourage adolescents to start smoking? Evidence from California. Prev Med 1999;28:1-11.

7 Sargent JD, Dalton MA, Beach M, et al. Cigarette promotional items in public schools. Arch Pediatr Adolesc promotional items in pubi

8 Murray DM, Perry CL. The measurement of substance use among adolescents: when is the 'bogus pipeline' method needed? Addict Behav 1987:12:225-33.

9 Evans RI, Hansen WB, Mittelmark MB. Increasing the validity of self-reports of smoking behavior in children. $f$ Appl Psychol 1977;62:521-3.

10 Bachman J, Johnston L, O'Malley P. Monitoring the future: questionnaire responses from the nation's high school seniors, 1991-1995. Ann Arbor, Michigan : Institute for Social Research, University of Michigan, 1996.

11 Stata Corporation. Stata reference manual. College Station, Texas: Stata Corporation, 1997

12 Landis JR, Koch GG. The measurement of observer agreement for categorical data. Biometrics 1977;33:671-9.

13 Collins L, Sussman S, Rauch J, et al. Psychosocial predictors of young adolescent cigarette smoking: a sixteen-month, three-wave longitudinal study. Fournal of Applied Social Psychology. 1987;17:554-73.

14 Kovar MG, Poe GS. The National Health Interview Survey design, 1973-84, and procedures, 1975-83. Washington DC:
US Department of Health and Human Services, Public US Department of Health and Human Services, Public Health

15 Pierce J, Farkas A, Evans N. Tobacco use in California 1992: a focus on preventing uptake in adolescents. Sacramento, California: California Department of Human Services, 1993

16 Pierce J, Choi W, Gilpin E, et al. Validation of susceptibility as a predictor of which adolescents take up smoking in the United States. Health Psychol 1996;15:355-61.
17 Evans N, Farkas A, Gilpin E, et al. Influence of tobacco marketing and exposure to smokers on adolescent susceptibility to smoking. F Natl Cancer Inst 1995;87:1538-45.

18 Everett SA, Schnuth RL, Tribble JL. Tobacco and alcohol use in top-grossing American films. F Community Health 1998;23:317-24.

19 McIntosh WD, Bazzini DG, Smith SM, et al. Who smokes in Hollywood? Characteristics of smokers in popular films from 1940 to 1989. Addict Behav 1998;23:395-8.

20 Hazan AR, Lipton HL, Glantz SA. Popular films do not reflect current tobacco use. Am f Public Health 1994; 84:998-1000.

21 Terre L, Drabmen RS, Speer P. Health-relevant behaviors in the media. Fournal of Applied Social Psychology 1991; $21: 1303-19$

22 Perkins H, Wechsler H. Variation in perceived college drinking norms and its impact on alcohol abuse: a nationwide study. Fournal of Drug Issues 1996;26:961-74.

23 Petraitis J, Flay BR, Miller TQ Reviewing theories of adolescent substance use: organizing pieces in the puzzle. Psychol Bull 1995;117:67-86.

24 Gerrard M, Gibbons FX, Benthin AC, et al. A longitudinal study of the reciprocal nature of risk behaviors and cognitions in adolescents: what you do shapes what you think, and vice versa. Health Psychol 1996;15:344-54.

25 Dalton MA, Sargent JD, Beach M, et al. Positive and negative expectations of smoking: implications for prevention. Prev Med 1999;29:460-6.

26 Swann WB, Jr. Self-verification: bringing social reality into harmony with the self. In: Suls J, Greenwald AG, eds. Psychological perspectives on the self. Hillsdale, New Jersey: Lawrence Erlbaum, 1983:33-66.

27 Chassin L, Presson CC, Sherman SJ, et al. Self-images and cigarette smoking in adolescents. Personality \& Social Psychology Bulletin 1981;7:670-6.

28 Burton D, Sussman S, Hansen WB, et al. Image attributions and smoking intentions among seventh grade students. Fournal of Applied Social Psychology. 1989;19:656-64.

29 Grube JW, Weir IL, Getzlaf S, et al. Own value system, value images, and cigarette smoking. Personality \& Social Psychology Bulletin. 1984;10:306-13.

30 Barton J, Chassin L, Presson CC, et al. Social image factors as motivators of smoking initiation in early and middle adolescence. Child Dev 1982;53:1499-511.

31 Chassin L, Presson C, Sherman SJ, et al. Psychosocial correlates of adolescent smokeless tobacco use. Addict Behav 1985;13:107-12.

32 Aloise-Young PA, Hennigan KM, Graham JW. Role of the self-image and smoker stereotype in smoking onset during early adolescence: a longitudinal study. Health Psychol 1996;15:494-7.

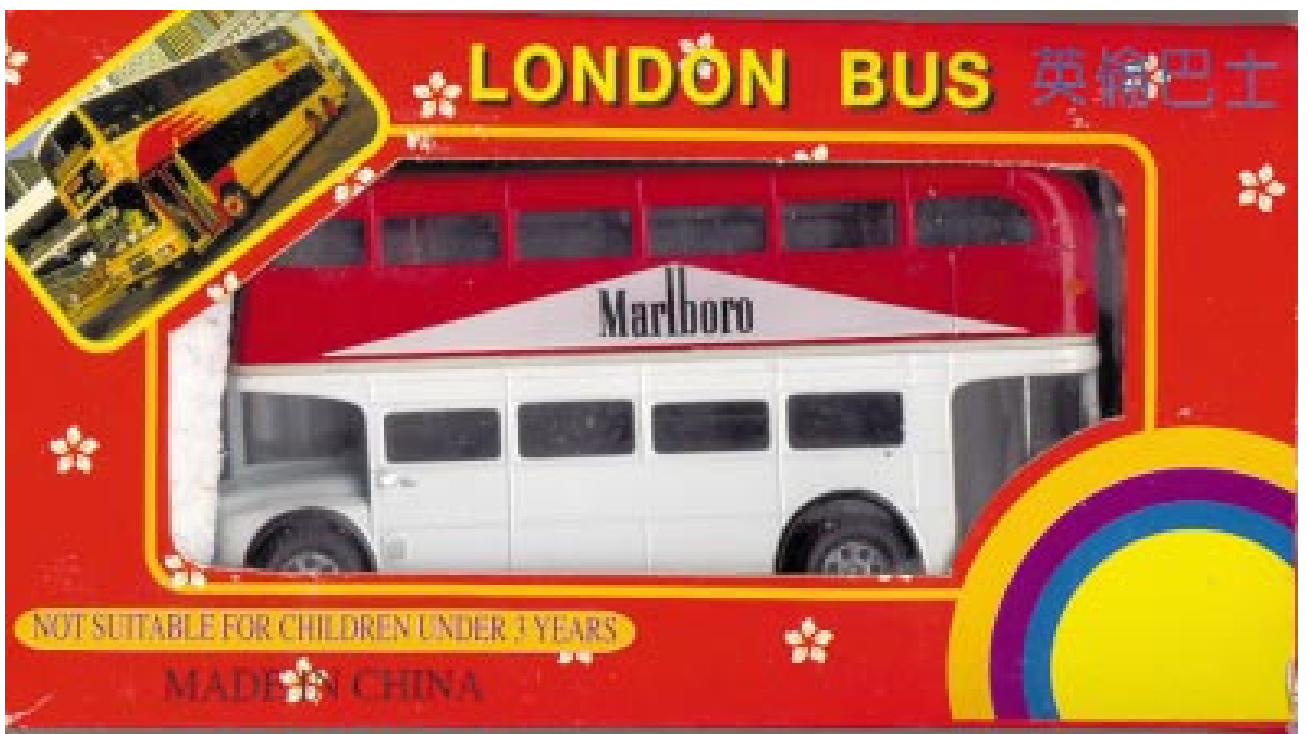

A toy London bus "not suitable for children under 3 years". Four year olds ... step right this way to Marlboro country! Photo supplied by Rick Pollay, Vancouver. 